\title{
Designing Tools for Collectively Solving Ill-Structured Problems
}

\author{
Hazbi Avdiji \\ Faculty of Business and \\ Economics, University of \\ Lausanne \\ hazbi.avdiji@unil.ch
}

\author{
Dina Elikan \\ Faculty of Business and \\ Economics, University of \\ Lausanne \\ dina.elikan@unil.ch
}

\author{
Stéphanie Missonier \\ Faculty of Business and \\ Economics, University of \\ Lausanne \\ stephanie.missonier@unil.ch
}

\author{
Yves Pigneur \\ Faculty of Business and \\ Economics, University of \\ Lausanne \\ yves.pigneur@unil.ch
}

\begin{abstract}
Ill-structured management problems are of paramount importance for organizations today. As they are complex to solve, they are undertaken by teams of diverse individuals who make use of tools to help them in solving such problems. Most tools either focus on supporting collaborative practices or are dedicated to solving specific ill-structured problems. In this paper, we bridge these two perspectives and provide design principles for tools that both support collaboration and are tailored for specific ill-structured problems. We derived these design principles from our participant observation of two critical cases of such collaborative tools: the Business Model Canvas and the Team Alignment Map. We lay the theoretical and design foundations for future developments of similar collaborative tools. Our paper illustrates the value that the IS discipline can bring to the increasing call for a design approach to management by rigorously developing tools for co-design.
\end{abstract}

\section{Introduction}

As today's business reality is characterized by illstructured, complex, and intangible management problems, work is increasingly carried out by teams of individuals [1],[2]. The potential of teams to solve such problems lies in the diversity of its member who contribute with their different backgrounds, knowledge domains, and expertise [3]. This potential has been acknowledged for various ill-structured management problems such as strategic management [4], [5] information systems development [6], [7] and new product development and service design [8],[9], [10],[11].

Collaboration is heavily mediated by tools and objects that are used by teams for the purpose of managing this diversity [12]. Therefore, there has been extensive research on collaborative tools and systems in disciplines such as Information Systems [13], Organization Studies [14], and Computer-Supported
Cooperative Work [15]. Such tools can take on many forms such as conceptual models, procedures, material artifacts, and information systems. Most contributions of these research strands resulted in collaborative tools and systems that facilitate the creation of a shared understand rising between diverse individuals (e.g.,[16],[17],[18]) facilitate communication and information exchange [19] support synchronous and asynchronous coordination between individuals (e.g., [20],[21]), and enhance group creativity (e.g.,[22], [23]).

While these tools have proven valuable to facilitate the process of collaboration, they do not directly support individuals in solving specific management problems. These tools are not tailored to the resolution of a certain classes of problems but have generic supportive functions. For example, when teams face the illstructured problem of executing and coordinating a plan of actions, they use a collection of objects and tools to solve it [24] as there is no tool that is specifically dedicated to that problem. The reliance on such a collection of objects and tools is not as effective and practical as relying on one tool and it increases the risk of divergence within team members [25].

In parallel, a survey conducted by Rigby \& Bilodeau [26] outlined that the tools most used by practitioners are tools that are dedicated to specific problems such as Total Quality Management, project planning, or strategic analyses. However, these tools remain analytical and even though they can be used by multiple individuals, they do not necessarily support a collaborative problem-solving and design approach which is crucial when teams face ill-structured problems ([27], [28]).

In this paper, we seek to bridge both these conceptions of tools by asking the following question: How to design collaborative tools that are tailored for specific ill-structured problems? 
We contribute to this question by proposing three design principles that lay the foundations for designing tools that support teams in collectively solving specific ill-structured problems. To do so, we performed longitudinal participant observation of the design process of two cases of such tools: (1) the Business Model Canvas that helps teams collectively solve strategic and business modeling problems and (2) the Team Alignment Map that supports teams in collectively solving the problem of coordination and execution. We use the cases as illustrations, because both were initially conceptual models for the specific problems they address and have iteratively been evolved into paper-based collaborative tools. Understanding the foundational principles of such collaborative tools allows us to build a solid ground from which future Computer-Aided Design (CAD) tools could be developed

\section{Literature review: Tools in collaboration}

Management is increasingly organized around teams solving ill-structured problems such as information systems development [6],[7], strategic management [29],[5], project scope definition [30], knowledge management [31], new product development and service design [8],[9],[10],[32] work organization and coordination [33],[2], and customer journey design [34], [35]. These problems are complex to solve as they are illdefined, difficult to frame, have ambiguous or unstable requirements, have various potential solutions, are often intangible and involve multiple and different stakeholders [36], [37], [38]. There is often limited consensus as of the appropriate solution, disagreement on how to proceed and no clear formulation of the problem itself [39].

Teams make use of a variety of tools and objects to augment their capabilities when navigating through such complexity [23],[12],[40]. Collaborative tools support collaboration by serving different purposes such as directing information sharing, augmenting the team members' capabilities to carry out certain tasks, directing and aligning work, enhancing inquiry and idea generation, guiding the perception and understanding of the problem at hand, motivating participation and cooperation [23],[14],[41].

Teams make use of such collaboration-support capabilities by using a collection of tools when solving ill-structured problems [24]. Depending on the stage of problem-solving they are in, team members use different configurations of tools [42],[40]. Some objects and tools will be used when framing the problem such as those that help teams create a shared understanding of their situation and revealing the interdependencies between team members while others will be used when solving the problem by helping them organize activities and coordinating their contributions [41]. However, Seidel and O'Mahony [25], found that using different tools and objects for solving a problem might lead to disunity within the team and ineffective collaboration as different objects create different understandings and representations, especially if they are not used by all team members across time.

Teams also use problem-support tools that address specific management problems. Such tools are in the form of conceptual artifacts that guide practitioners' reflection (e.g., the SWOT analysis, the strategic alignment model). However, these tools remain purely analytical and are not designed for collaborative use which proves problematic in the context of ill-structured problems which require collaboration of diverse individuals [27], [43].

These two strands of research suggest that there is a need for practitioners to use tools that both support collaboration and help them solve specific ill-structured problems. These needs have led to a recent generation of tools that guide collaboration for specific illstructured problems that were inspired by the Business Model Canvas [55]. Such tools reconcile both streams of research on tools - those that focus on collaboration support and those that focus on management problems and propose a paradigm shift.

Tools such as the Project Canvas [44] or the Customer Journey Mapping Game [45] reuse the visual aspects of the Business Model Canvas in which dimensions of a problem are displayed as empty boxes that team members collaborate to fill using sticky notes. Except for the Business Model Canvas, it is not clear how theoretically and conceptually sound their components are as they have mostly been designed only by business practitioners. This proves problematic as these components shape how team members frame a problem, which might lead to ineffective problemsolving. In other words, we need design principles which would support the rigorous design of such tools. Therefore, the following question arises: How to design collaborative tools that are tailored for specific illstructured problems?

\section{Methodology}

To answer our research question, we relate two case studies [46] of the design process of two collaborative tools that support collaboration for two specific ill- 
structured management problems: the Business Model Canvas for strategy and business modeling and the Team Alignment Map for coordination and execution.

Both tools represent critical cases as they are among the few representative examples of the collaborative tools that our research questions target and were designed based on theoretically sound and rigorous academic works. Moreover, both tools have attracted considerable interest by practitioners. The Business Model Canvas is used by more than 5 million people globally [47] and is arguably a quasi-standard in the field [48] .The Team Alignment Map was developed in June 2016 and has since then attracted more than 400 requests for proposals and training.

The selection of these cases was also motivated by their potential for replication [49] as there are extensive similarities and differences between the two cases (Table 1). The cases are similar in that (1) both tools are collaborative, (2) they address ill-structured management problems, (3) were part of design science research projects, (4) their design and evaluation involved strong implication and participation of endusers and practitioners in the design and evaluation of the tools, and (5) the tools are similar in their use. The cases are different in that (1) they do not address the same problems as one focuses on business modeling while the other is tailored to coordination and alignment, and (2) they were developed independently by two different teams.

Data on the design process of both tools was collected through participant observations and a total of 10 interviews with the co-designers. The observation ranged from September 2008 to November 2010 for the Business Model Canvas, which consists of 470 hubs and from September 2013 to this date for the Team Alignment Map. Our observation also covers the periods before the design of the tools which allowed us to gather data on intermediary instantiations and artifacts that led to the current versions of the tools.

The data analysis was performed by comparing the design process of both tools. Similarities in the design and the properties of the tools allowed us to define an initial set of design principles for developing collaborative tools that address specific ill-structured problems. These principles were then refined by taking into account the differences of the cases. Design principles "define the structure, organization, and functioning of the design product or design method" [50].
As suggested by [51], design principles can be validated by evaluating the artifact from which they were drawn. We followed their guidelines and evaluated the tools' usefulness, efficacy, and usability. Moreover, [52] and [53] suggest that the demonstration of rigor in design can be evaluated through case studies.

\section{Cases descriptions and evaluations}

In this section, we describe both cases by outlining the purpose of the two tools. We also relate the evaluation of the tools.

\subsection{The Business Model Canvas}

The Business Model Canvas is a tool for business model development [54] .The Canvas defines business models to consist of nine components, and presents these components through a visual template in the form of a paper-based F1 poster to facilitate generating and communicating business model ideas. In practice, the Canvas has become the quasi-standard for describing business models [50].

The Business Model Canvas is seen as essential for entrepreneurs to keep a constant reflection and for developing their business model [55]. Some go further by stating that the Business Model Canvas is arguably the most important tool for this purpose [7]. Moreover, the tool has attracted tremendous interest in practice as the designers of the tool state that more than 5 million of the tool were made globally [47]. The impact of the Canvas is not limited to practice as the book describing the tool has been referenced by more than 5,000 academic studies according to Google Scholar.

Adding to that, Trimi and Bergebal-Mirabent., [55] also states that the Canvas is useful for collaboration, as it facilitates communication among stakeholders, becoming the starting point of strategic discussion around the business activities of the company.

\subsection{The Team Alignment Map}

The Team Alignment Map is the most recent instantiation of a series of tools that are part of the same design science research project. These instantiations were all developed for the purpose of team coordination. All instantiations are based on Clark's psycholinguistic theory on joint activities [56]. 


\begin{tabular}{|l|l|l|}
\hline \multicolumn{1}{|c|}{ Design Principle } & \multicolumn{1}{|c|}{$\begin{array}{l}\text { Illustration in the Business Model } \\
\text { Canvas case }\end{array}$} & $\begin{array}{l}\text { Illustration in the Team Alignment } \\
\text { Map case }\end{array}$ \\
\hline $\begin{array}{l}\text { Design principle 1: Frame the ill-structured } \\
\text { problem by developing an ontology in which } \\
\text { the main components of the problem and } \\
\text { their relationships are modeled. }\end{array}$ & $\begin{array}{l}\text { Development of a "Business Model } \\
\text { Ontology" relying on the Ushold and } \\
\text { King (1995)'s methodology to build an } \\
\text { ontology from the existing literature } \\
\text { business modeling }\end{array}$ & $\begin{array}{l}\text { Development of a conceptual model } \\
\text { translated from Clark (1996)'s theory } \\
\text { on coordination. }\end{array}$ \\
\hline $\begin{array}{l}\text { Design principle 2: Represent the ontology } \\
\text { into a shared visualization by deriving a } \\
\text { concept map from the ontology and } \\
\text { structuring the concepts logically into a } \\
\text { visual empty problem space. }\end{array}$ & $\begin{array}{l}\text { Transforming the Ontology into the } \\
\text { Business Model Canvas, by deriving the } \\
\text { most important concepts from the } \\
\text { ontology and placing them into a visual } \\
\text { space. }\end{array}$ & $\begin{array}{l}\text { Development of several visual artifacts } \\
\text { (cards, mobile application and maps) } \\
\text { that were tested by users. The Map with } \\
\text { during their meetings. }\end{array}$ \\
\hline $\begin{array}{l}\text { Design principle 3: Instantiate the } \\
\text { visualization into a shared support in order to } \\
\text { use it as a problem space on which solutions } \\
\text { can be prototyped. Sticky notes are used to } \\
\text { add, remove or change the content within } \\
\text { each empty space as the discussion unfolds. }\end{array}$ & $\begin{array}{l}\text { The authors propose to print the paper- } \\
\text { based tool on a big format and to write } \\
\text { all the possible solutions for the } \\
\text { problems on sticky notes that will then be } \\
\text { placed on their corresponding problem } \\
\text { space. }\end{array}$ & $\begin{array}{l}\text { The authors propose to print the paper- } \\
\text { based tool on a big format and to write } \\
\text { all the possible solutions for the } \\
\text { be placed on their corresponding } \\
\text { problem space. }\end{array}$ \\
\hline
\end{tabular}

Table 1. Design Principles for collaborative tools for solving ill-structured problems

Previous instantiations were validated and published in an A-ranked IS journal and conference by the designers [57], [58]. The Team Alignment Map was recently tested in ten teams with seven informants, four of whom were project managers and three were coaches supporting the team.

The Team Alignment Map was perceived by the seven interviewees as easy, simple, and straightforward to use, hence providing evidence for the ease of use of the tool.

All informants considered the tool as useful for their teams to co-design their coordination as it allowed everyone to take part actively in the discussions on the four dimensions. One informant reported that using the Map "is not so much filling it out and assigning roles and responsibilities to people. It's more 'okay here are the main points we need to make sure that we cover"

Using the tool led all teams to conclude on a social contract on the four elements of their joint activity. One informant defined the Team Alignment Map as "some sort of contract where everyone is saying 'Okay, I commit to this'. It's in writing, it's in front of us".

Moreover, five out of seven informants said that he tool easily allowed them to prototype different versions of the Team Alignment Map as sticky notes were easy to add, remove, and amend.
Overall, all the informants regarded the Team Alignment Map as useful for co-designing coordination.

\section{Cases analysis}

We analyzed data from the development process of both tools. Based on the similarities and the differences between the two, we derive three design principles that should inform the design of collaborative tools that support teams in solving specific ill-structured management problems (Table 1). Hereafter we describe the three design principles and illustrate how we derived them by describing the development process that took place for both tools.

\subsection{Design principle 1: Framing the ill- structured problem through an ontology}

The first design principle aims at framing the illstructured problem by developing an ontology with all its elements and their relationships.

Design principle 1: Frame the ill-structured problem by developing an ontology in which the main components of the problem and their relationships are modeled.

Ontologies allow to better define a problem as well as its underlying concepts and relationships. As stressed by [38], the most important and difficult task in a 
problem-solving activity is to provide structure to a problem when there is none apparent. Among the multiple means to structure a collaborative problem, ontologies have long been used and proven valuable when designing artifacts [59],[60]. It provides participants with a collective frame to understand all the elements they need to think of and discuss for a given illstructured problem [61]. Based on this structure, participants can envision and collectively generate different solutions. Thus, ontologies reduce conceptual and lexical confusion by providing a unifying framework within an organization [62].

The first step of the development of the Business Model Canvas started with Osterwalder's thesis [62] and a first article [63] in which Osterwalder and Pigneur tried to understand how business models could be described and represented so that tools and concepts could be developed for business modeling. To tackle this question, they designed a rigorous conceptual model of business models, which they called the Business Model Ontology (BMO). The goal of this ontology was to define the main components of business models and their relationships.

To develop BMO, Osterwalder and Pigneur [63] followed Uschold \& King's [64] methodology for building ontologies: (1) they identified the key concepts and relationships in the domain of business models, (2) they produced precise and unambiguous text definitions for the concepts and their relationships, (3) they identified the terms to refer to these concepts and relationships using labels. By following this process, they identified nine elements (or building blocks) for the business model ontology, which they represented as a set of boxes which were related by arrows to depict their relationships. Figure 1 shows this representation of the different elements and how they relate to each other. The nine building blocks all result from an extensive literature review.

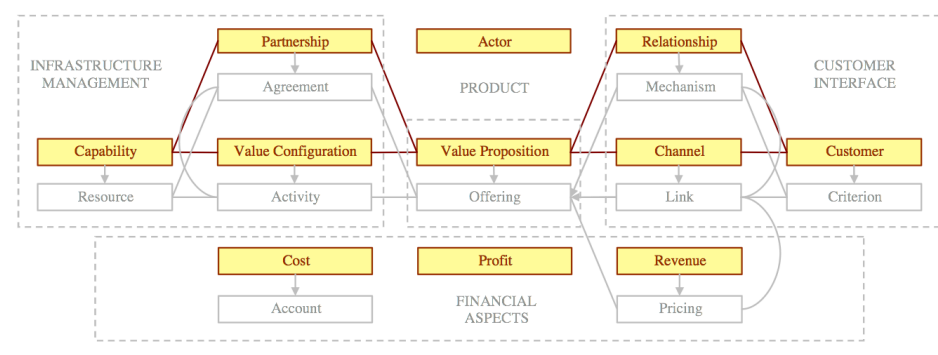

Figure 1. Business Model Ontology

The design of the Team Alignment Map started with a study published in an A-ranked journal in IS.. The aim of the study was to develop an ontology for team coordination based on Clark (1996)'s theory on joint activities and coordination. The goal was to instantiate his theory into a set of cards that project managers could use as visual support during their team meetings to remember the main elements they should discuss for them to coordinate effectively.

The development of the Team Alignment Map's ontology was also based on prior literature. This ontology proved valuable as it addressed the content of conversations, unlike other accounts of coordination that focus on organizational design or implicit coordination[41].

\subsection{Design principle 2: Representing the problem structure into a shared visualization}

The second design principle consists of developing a visual representation of the ontology that is shared by all participants so that they can all refer to the same structure of the problem.

\section{Design principle 2: Represent the ontology into a shared visualization by deriving a concept map from the ontology and structuring the concepts logically into a visual empty problem spaces.}

Shared visualization focuses everyone's attention on a common frame. It helps avoid ambiguities in the discussion and how the problem is framed and understood between the stakeholders [65],[66]. If the stakeholders use the semantics of the display to configure their discussion, they decrease the risk of semantic confusion and ambivalences [67]. The benefits of visual templates, as compared to purely textual or verbal communication modes, are to be found in their structure, which offers a "representational guidance" [61].

The Business Model Ontology was instantiated into a shared visual tool, i.e. the Business Model Canvas [54] (Figure 2). The most important components unfolded during the ontology development were kept. The relationships were used to set the order of the different components. A conceptual map was built upon the ontology, to relate all the concepts. The conceptual map was the basis to the structure of the visual instantiation. Concept maps have an additional level of abstraction compared to ontologies which makes them less complex to understand and use. The Canvas was designed by the authors, having in mind the ontology (i.e., the main concept and their relationships) but also the goals of the instantiated tool. These goals included (1) the business model tool should help business 
practitioners understand a business model and the relationships behind its elements more quickly, and (2) it should create a common language to improve communication between the stakeholders when addressing business model issues [68]. One of the hypotheses behind these goals was that a visualization tool would improve the quality of communication between stakeholders and allow them to co-design business models more easily.

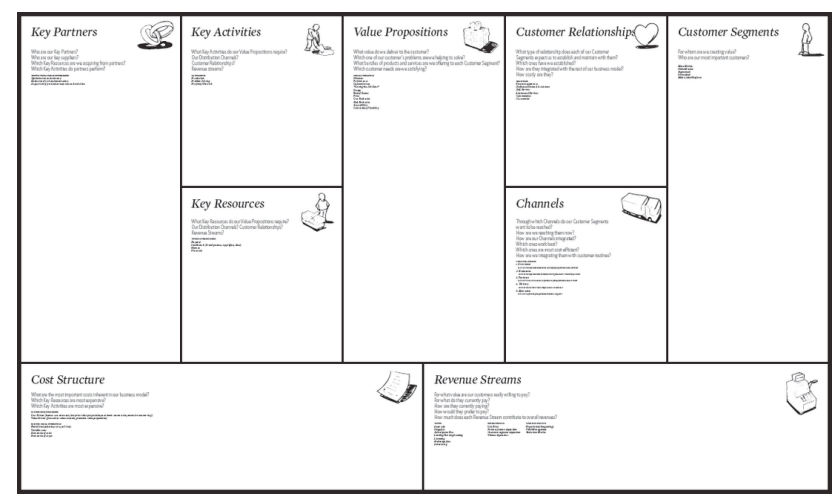

Figure 2. Business Model Canvas

For the Team Alignment Map, Clark's terminology was deliberately translated into shorter concepts in order to ensure the parsimony of a conceptual map. The ontology of the Team Alignment Map was instantiated into several artifacts among which a set of cards, a web application, and the Team Alignment Map. These intermediary artifacts were tested in different organizations and settings [57], [58]. Results of the study showed that repeated use of the cards during by the project manager during team meetings to direct the content of the team's discussions helped reduce coordination breakdowns and proved helpful for teams to align their contributions effectively.

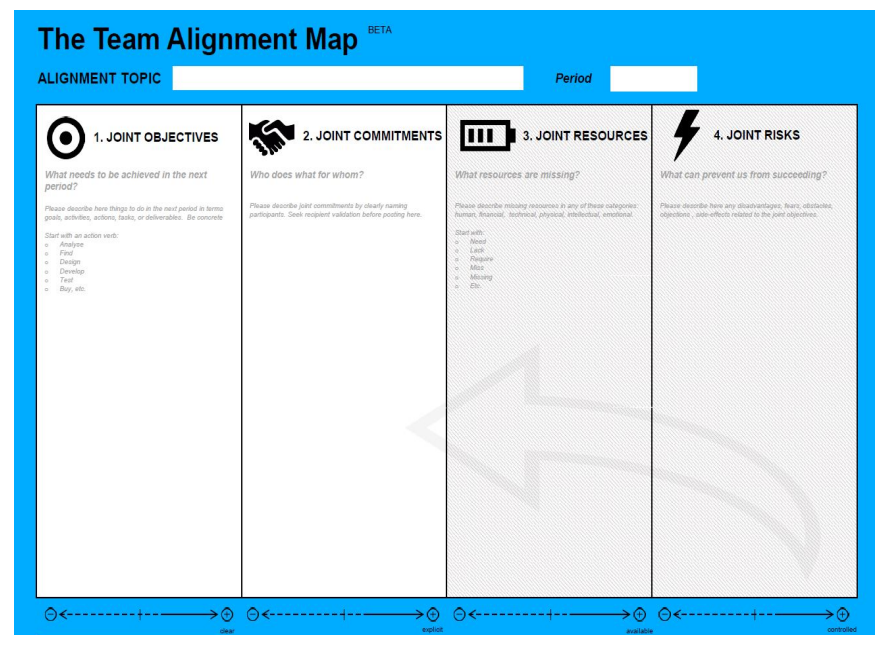

Figure 3. Team Alignment Map
Despite that, the designers of the tool received extensive feedback from users who stressed their willingness not only to have visual support during team meetings, but rather have a tool that would allow all team members to define the content of the four dimensions by filling them with elements. Therefore, the current version of the tool represents the four dimensions of the ontology as four empty spaces on a printed F1 poster, ranging from left to right as they should be addressed in this order during conversations (Figure 3).

\begin{tabular}{|c|c|c|}
\hline $\begin{array}{l}\text { Clark (1996)'s } \\
\text { requirements } \\
\text { for coordination }\end{array}$ & $\begin{array}{l}\text { Mastrogiac } \\
\text { omo et al. } \\
(2014) \text { 's } \\
\text { conceptual } \\
\text { model }\end{array}$ & Description \\
\hline $\begin{array}{l}\text { 1. Identification: } \\
\text { Two individuals } \\
\text { (A and B) must } \\
\text { identify } r \text { (the } \\
\text { joint purpose) }\end{array}$ & $\begin{array}{l}\text { Variable: } \\
\text { Joint } \\
\text { objectives }\end{array}$ & $\begin{array}{l}\text { What the participants } \\
\text { intend to do } \\
\text { together }\end{array}$ \\
\hline \multirow{2}{*}{$\begin{array}{l}\text { 2. Ability: it must } \\
\text { be possible for A } \\
\text { and B to play } \\
\text { their part in } \\
\text { fulfilling } r\end{array}$} & $\begin{array}{l}\text { Variable: } \\
\text { joint } \\
\text { resources }\end{array}$ & $\begin{array}{l}\text { What the participants } \\
\text { need to play } \\
\text { their part }\end{array}$ \\
\hline & $\begin{array}{l}\text { Variable: } \\
\text { joint risks }\end{array}$ & $\begin{array}{l}\text { What could prevent } \\
\text { participants from } \\
\text { playing their part }\end{array}$ \\
\hline $\begin{array}{l}\text { 3. Willingness: A } \\
\text { and B must be } \\
\text { willing to play } \\
\text { their part in } \\
\text { fulfilling } \mathrm{r}\end{array}$ & $\begin{array}{l}\text { Variable: } \\
\text { joint } \\
\text { commitment } \\
\text { s }\end{array}$ & $\begin{array}{l}\text { What participants } \\
\text { expect each other } \\
\text { to do }\end{array}$ \\
\hline $\begin{array}{l}\text { 4. Mutual belief: } \\
\text { A and B must } \\
\text { each believe that } \\
1,2,3 \text {, and } 4 \text { are } \\
\text { part of their } \\
\text { common ground }\end{array}$ & $\begin{array}{l}\text { Process: } \\
\text { team } \\
\text { meetings }\end{array}$ & $\begin{array}{l}\text { Seek evidence of } \\
\text { mutual } \\
\text { understanding for joint } \\
\text { objectives, } \\
\text { joint commitments, } \\
\text { joint resources, } \\
\text { and joint risks in team } \\
\text { meetings or } \\
\text { project-related } \\
\text { conversations }\end{array}$ \\
\hline
\end{tabular}

Table 2. Team Alignment Ontology

\subsection{Design principle 3: Using the shared visualization for co-design}

The third design principle consists of using the to codesign a solution to their ill-structured problem. Codesign is an iterative process of inquiry and co-creation 
in which team members tap on their diverse set of knowledge, experiences, and insights to create an artifact - be it conceptual or material - that participates in solving their common problem [69],[70],[32]. The shared visualization thus acts as a shared problem space for collective contributions.

Design principle 3: $\quad$ Instantiate the visualization into a shared support in order to use it as a problem space on which solutions can be prototyped. Sticky notes are used to add, remove or change the content within each empty space as the discussion unfolds.

Co-design has several benefits to address illstructured management problems: it allows teams to make use of their diversity to generate better ideas, it promotes a trial-and-error approach to solving the problem, and it increases the level of commitment and satisfaction with the solution [32].

Because the Business Model Canvas aims at helping users co-design business models, its designers have instantiated the nine elements of the business model ontology as building blocks on a shared large print paperbased canvas. As the Canvas is visualized by all participants, the nine building blocks provide a structure for group reflection and discussion in which all participants actively and collaboratively participate. Each block is depicted as an empty space that users discuss and fill with sticky notes on which they write elements of the solution of the organizations' building blocks. The sticky notes can easily be added, amended, or removed as the group discussion and reflection unfolds. The tool supports co-design as it allows team members to jointly discuss and define the business model problem they face, and discuss and explore alternative solutions, as has been identified by Steen [11].

For the use of the Team Alignment Map, the designers relied on some users' insights and on the theoretical accounts of coordination [33] and [2] and also decided to prescribe the use of the tool with co-design techniques. In fact, team coordination is an iterative and discursive process when individuals need to coordinate for new joint activities or when problems occur [33]. The co-design technique that is promoted and prescribed is collaborative design and prototyping using sticky notes. Team members thus display the Team Alignment Map either in the same meeting room in collocated settings or as a shared document during online meetings. All participants write what they think are the joint objectives, commitments, resources, and risks on sticky notes. Participants then aggregate all their ideas and evaluate them during open discussions where they negotiate which elements to keep, add, remove, or amend. They prototype their coordination until a mutually satisfactory solution is reached.

\section{Discussion}

The question we asked in this paper related to how to design collaborative tools that are tailored to specific ill-structured problems. Our results answer this question by advising designers how to develop such tools.

More specifically, we suggest that ill-structured problems would benefit from being well-framed and solved collaboratively. We can do so by using an ontology that defines the components of the problem and their relationships. This ontology should then be instantiated into a shared visualization where components are represented as empty spaces and arranged according to their relationships. This allows individuals to fill the empty spaces with elements of the solution they are co-designing. Using sticky notes can prove practical as it allows team members to easily fill the columns and remove or amend any elements as they develop better alternatives or point out at inconsistencies. This supports the trial-and-error inquiry that characterizes co-design [54], [11].

As all participants all share the same visualization of the problem and the sticky notes, which represent the same solutions, they can easily assess the components of the given problem and address any potential inconsistencies. They can also model different solutions on the same visual representation and compare them. In summary, the shared representation supports participants in discussing, analyzing and generating ideas when co-designing solutions to ill-structured problems.

While visualization can take on different forms [71] our cases inform that visualization and the way the tool is to be used are interrelated. In both cases, the designers opted for a shared visualization in which concepts are depicted as empty spaces so that team members could use them as problem spaces in which they can co-design solutions. This visualization type has also been noted by Comi \& Bresciani [72] as valuable for designing solutions to problems. We consider this type of shared visualization to be the differentiating point between both cases and the other collaborative tools that we outlined in the literature review. The two cases also inform us on the need for parsimonious visualization to ensure easeof-use. Designers then need to find a balance between the completeness of the ontology to be represented and 
parsimony. This balance can be reached through testing and evaluation with practitioners.

We also note from our cases that developing ontologies requires considerable effort and inquiry. However, it is important that the ontologies be rigorously developed and tested to ensure that the problem is correctly represented. Designers can follow the guidelines by Gomez-Pérez [73] who advises that ontologies be assessed for their consistency, completeness, and conciseness. We stress the importance of this part as problem representation is the most critical part in problem-solving [74]. Both our cases had different strategies for developing their ontologies as the Business Model Ontology was developed by the designers of the tool based on an extensive literature review, whereas because the field of collaboration was already more mature, the ontology of the Team Alignment Map was derived from Clark's theory on coordination.

Moreover, our study informs on the need for evaluation. Both the Business Model Canvas and the Team Alignment Map were tested and evaluated iteratively: first for their ontology, then their visualization and finally the techniques of usage. The evaluation was also done in different settings and contexts. Feedback from practitioners helps refine the tool as long as its usefulness, usability, and efficacy are not satisfactory.

Finally, our design principles cannot substitute for one another. The three design principles are to be considered by designers as fundamental requirements for designing such collaborative tools. In fact, our design principles appear to be extensively interrelated and their value cannot be decomposed: they participate in creating valuable artifacts only when combined. To some extent, these principles could be regarded as the bridge between both strands of collaborative tools that we outlined in the literature review, i.e. those that support collaboration and those that are tailored for specific management problems.

\section{Conclusion \& Future Work}

Our paper is to be regarded as the initial step toward the generation of a "toolbox" to help management teams co-design solutions mostly but not exclusively to illstructured problems. This toolbox could address a variety of problems in which each problem would have a tool dedicated to it. It is important to note that this toolbox would not imply that all other collaborative tools would be replaced, rather that it would come in support whenever teams face specific problems. In the case of well-structured problems, there already exists classical, rational decision making tools. But design thinking approaches are becoming increasingly popular even for well-structured problems. Thus, we could also imagine a new generation of tools for these types of problems, even though it is less needed. [8]

The two ill-structured problems we presented are not specific to one organization. Our design principles can thus be replicated across organizations. Therefore, our design principles could be replicated and tested for other ill-structured projects such as co-designing brand identities, business processes, or data quality management. In that regard, our paper assists the recent emergence of visually shared collaborative tools which have stressed the need for practitioners to have such tools.

We believe that the IS discipline has an important and central role to play in this endeavor. In fact, the cores of our three design principles - ontologies, shared visualization, co-design - have seen extensive developments but in different domains rather in isolation from one another. Ontologies have long been used in engineering and academic research. Visualization has received increasing interest in the business practice as the number of recent books on the subject illustrate it. Finally, co-design has recently emerged as a valuable approach to collaboration in innovation and design thinking. Through its recent tradition with design science research, the IS discipline is familiar with all three domains, i.e. engineering academic research, the business practice, and design thinking. We thus join Osterwalder and Pigneur's [27] conclusion on the potential for our discipline to provide management research and practice with collaborative tools for co-design.

These tools could also be in the form of ComputerAided Design. Such tools would augment management team's capabilities to co-design solutions to illstructured problems. This underlines the importance of first understanding the fundamental requirements and the spirit of such tools, which we started to formulate from paper-based tools.

We hope that our study will help both practitioners and researchers develop new tools that would instill a new way of managing and working. As various scholars have called for design in management [8],[10], we believe that tools developed based on our design principles can help practitioners adopt a design approach, even for those who are not familiar or trained with co-design. 


\section{References}

[1] B. A. Bechky, "Gaffers, gofers, and grips: Role-based coordination in temporary organizations," Organ. Sci., vol. 17, no. 1, pp. 3-21, 2006.

[2] H. Minssen, "Challenges of teamwork in production: demands of communication," Organ. Stud., vol. 27, no. 1, pp. 103-124, 2006.

[3] A. C. Edmondson and J.-F. Harvey, "Cross-boundary teaming for innovation: Integrating research on teams and knowledge in organizations," Hum. Resour. Manag. Rev., 2017.

[4] M. Bruce and J. R. Bessant, Design in business: Strategic innovation through design. Pearson education, 2002.

[5] M. Sosna, R. N. Trevinyo-Rodríguez, and S. R. Velamuri, "Business model innovation through trial-and-error learning: The Naturhouse case," Long Range Plann., vol. 43, no. 2, pp. 383-407, 2010.

[6] K. Dorst, "The core of 'design thinking'and its application," Des. Stud., vol. 32, no. 6, pp. 521-532, 2011.

[7] T. John and D. Kundisch, "Why Fit Leads to Surprise: An Extension of Cognitive Fit Theory to Creative Problems," 2015.

[8] R. J. Boland Jr, F. Collopy, K. Lyytinen, and Y. Yoo, "Managing as designing: lessons for organization leaders from the design practice of Frank O. Gehry," Des. Issues, vol. 24, no. 1, pp. 10-25, 2008.

[9] T. Brown, "Change by design," 2009.

[10] M. Gruber, N. De Leon, G. George, and P. Thompson, "Managing by design," Acad. Manage. J., vol. 58, no. 1, pp. 17, 2015.

[11] M. Steen, "Co-design as a process of joint inquiry and imagination,” Des. Issues, vol. 29, no. 2, pp. 16-28, 2013.

[12] K. K. Cetina, "Sociality with objects: Social relations in postsocial knowledge societies," Theory Cult. Soc., vol. 14, no. 4, pp. 1-30, 1997.

[13] J. F. Nunamaker Jr, R. O. Briggs, D. C. Derrick, and G. Schwabe, "The last research mile: Achieving both rigor and relevance in information systems research," J. Manag. Inf. Syst., vol. 32, no. 3, pp. 10-47, 2015.

[14] D. Nicolini, J. Mengis, and J. Swan, "Understanding the role of objects in cross-disciplinary collaboration," Organ. Sci., vol. 23, no. 3, pp. 612-629, 2012.

[15] G. Fitzpatrick and G. Ellingsen, "A review of 25 years of CSCW research in healthcare: contributions, challenges and future agendas," Comput. Support. Coop. Work CSCW, vol. 22, no. 4-6, pp. 609-665, 2013.

[16] E. A. C. Bittner and J. M. Leimeister, "Creating shared understanding in heterogeneous work groups: Why it matters and how to achieve it," J. Manag. Inf. Syst., vol. 31, no. 1, pp. 111-144, 2014.

[17] R. Harper, "From I-awareness to we-awareness in CSCW: A review essay," Comput. Support. Coop. Work CSCW, vol. 25, no. 4-5, pp. 295-301, 2016.

[18] G. Mangalaraj, S. P. Nerur, R. Mahapatra, and K. H. Price, "Distributed Cognition in Software Design: An Experimental Investigation of the Role of Design Patterns and Collaboration.," Mis Q., vol. 38, no. 1, pp. 249-274, 2014.

[19] E. B. Kerr and S. R. Hiltz, Computer-mediated communication systems: Status and evaluation. Academic Press, 2013.

[20] S. Kudaravalli, S. Faraj, and S. L. Johnson, "A Configural Approach to Coordinating Expertise in Software Development Teams.," MIS Q., vol. 41, no. 1, 2017.

[21] D. M. Thomas and R. P. Bostrom, "Team leader strategies for enabling collaboration technology adaptation: team technology knowledge to improve globally distributed systems development work," Eur. J. Inf. Syst., vol. 19, no. 2, pp. 223-237, 2010.

[22] M. Bogers and W. Horst, "Collaborative prototyping: Cross-fertilization of knowledge in prototype-driven problem solving," J. Prod. Innov. Manag., vol. 31, no. 4, pp. 744-764, 2014.

[23] P. Dalsgaard, "Instruments of inquiry: Understanding the nature and role of tools in design," Int. J. Des., vol. 11, no. 1, 2017.

[24] H. Scarbrough, M. Robertson, and J. Swan, "Diffusion in the face of failure: The evolution of a management innovation," Br. J. Manag., vol. 26, no. 3, pp. 365-387, 2015. [25] V. P. Seidel and S. O'Mahony, "Managing the repertoire: Stories, metaphors, prototypes, and concept coherence in product innovation," Organ. Sci., vol. 25, no. 3, pp. 691-712, 2014.

[26] D. Rigby, "Management Tools \& Trends 2013/Darrell Rigby and Barbara Bilodeau," Bain Co. INSIGHTS Retrieved Httpwww Bain Compublicationsarticlesmanagement-Tools-Trends-2013 Aspx.

[27] A. Osterwalder and Y. Pigneur, "Designing business models and similar strategic objects: the contribution of IS," J. Assoc. Inf. Syst., vol. 14, no. 5, p. 237, 2013.

[28] M. Pacanowsky, "Team tools for wicked problems," Organ. Dyn., vol. 23, no. 3, pp. 36-51, 1995.

[29] J. C. Camillus, "Strategy as a wicked problem," Harv. Bus. Rev., vol. 86, no. 5, p. 98, 2008.

[30] M. Whelton and G. Ballard, "Wicked problems in project definition," presented at the Proceedings of the International Group for Lean Construction 10th Annual Conference, Brazil, 2002.

[31] K. Crawford, H. Hasan, L. Warne, and H. Linger, "From traditional knowledge management in hierarchical organizations to a network centric paradigm for a changing world," Emergence Complex. Organ., vol. 11, no. 1, p. 1, 2009.

[32] M. Steen, M. Manschot, and N. De Koning, "Benefits of co-design in service design projects," Int. J. Des., vol. 5, no. 2, 2011.

[33] B. A. Bechky and G. A. Okhuysen, "Expecting the unexpected? How SWAT officers and film crews handle surprises," Acad. Manage. J., vol. 54, no. 2, pp. 239-261, 2011.

[34] J. Hobbs and T. Fenn, "Navigating Indeterminacy through the application of User Journeys," presented at the Proceedings of the 3rd International Conference on Design, Development and Research. Kumasi, Ghana, 2013, pp. 190209.

[35] F. Lemke, M. Clark, and H. Wilson, "Customer experience quality: an exploration in business and consumer contexts using repertory grid technique," J. Acad. Mark. Sci., 
vol. 39, no. 6, pp. 846-869, 2011.

[36] K. Dorst, "Design problems and design paradoxes," Des. Issues, vol. 22, no. 3, pp. 4-17, 2006.

[37] B. Kogut and U. Zander, "Knowledge of the firm, combinative capabilities, and the replication of technology," Organ. Sci., vol. 3, no. 3, pp. 383-397, 1992.

[38] H. A. Simon, "The structure of ill structured problems," Artif. Intell., vol. 4, no. 3-4, pp. 181-201, 1973.

[39] Lundmark LW, Nickerson, JA, Derrick, D. 2017. Wicked Problem Formulation: Models of Cognition in the Design and Selection of Valuable Strategies. Academy of Management Proceedings. doi 10.5465AMBPP.2017.17551

[40] K. Lindberg and L. Walter, "Objects-in-use and organizing in action nets: A case of an infusion pump," $J$. Manag. Inq., vol. 22, no. 2, pp. 212-227, 2013.

[41] G. A. Okhuysen and B. A. Bechky, "10 coordination in organizations: An integrative perspective," Acad. Manag. Ann., vol. 3, no. 1, pp. 463-502, 2009.

[42] C.-F. Lee and M. Amjadi, "The role of materiality: Knowing through objects in work practice," Eur. Manag. J., vol. 32, no. 5, pp. 723-734, 2014.

[43] D. J. Teece, "Business models, business strategy and innovation," Long Range Plann., vol. 43, no. 2, pp. 172-194, 2010 .

[44] F. Habermann and K. Schmidt, "The project canvas. A visual tool to jointly understand, design, and initiate projects," 2014.

[45] J. Kalbach, Mapping Experiences: A Complete Guide to Creating Value Through Journeys, Blueprints, and Diagrams. O'Reilly Media, Inc., 2016.

[46] R. K. Yin, Case study research: Design and methods. Sage publications, 2013.

[47] A. Strategyzer, "The Business Model Canvas. Retrieved at January 10, 2016," 2015.

[48] P. Spieth, D. Schneckenberg, and J. E. Ricart, "Business model innovation-state of the art and future challenges for the field," RD Manag., vol. 44, no. 3, pp. 237-247, 2014.

[49] M. B. Miles and A. M. Huberman, "Qualitative data analysis: A sourcebook," Beverly Hills Sage Publ., 1994.

[50] D. Jones and S. Gregor, "The formulation of an information systems design theory for e-Learning," presented at the First International Conference on Design Science Research in Information Systems and Technology, Claremont, CA, 2006, pp. 356-373.

[51] S. Gregor and A. R. Hevner, "Positioning and presenting design science research for maximum impact.," MIS $Q$., vol. 37, no. 2, pp. 337-355, 2013.

[52] K. Peffers, T. Tuunanen, M. A. Rothenberger, and S. Chatterjee, "A design science research methodology for information systems research," J. Manag. Inf. Syst., vol. 24, no. 3, pp. 45-77, 2007.

[53] J. Venable, J. Pries-Heje, and R. Baskerville, "A comprehensive framework for evaluation in design science research," presented at the International Conference on Design Science Research in Information Systems, 2012, pp. 423-438. [54] A. Osterwalder and Y. Pigneur, Business model generation: a handbook for visionaries, game changers, and challengers. John Wiley \& Sons, 2010.

[55] S. Trimi and J. Berbegal-Mirabent, "Business model innovation in entrepreneurship," Int. Entrep. Manag. J., vol. 8, no. 4, pp. 449-465, 2012.

[56] C. Clark et al., "Collaboration as dialogue: Teachers and researchers engaged in conversation and professional development," Am. Educ. Res. J., vol. 33, no. 1, pp. 193-231, 1996.

[57] S. Mastrogiacomo, S. Missonier, and R. Bonazzi, "Talk before it's too late: Reconsidering the role of conversation in information systems project management," J. Manag. Inf. Syst., vol. 31, no. 1, pp. 47-78, 2014.

[58] S. Missonier, H. Avdiji, and S. Mastrogiacomo, "APPLYING PSYCHOLINGUISTIC CONCEPTS TO IS PROJECT MANAGEMENT TOOL DESIGN," 2014.

[59] N. Guarino, "Formal ontology and information systems," presented at the Proceedings of FOIS, 1998, vol. 98, pp. 8197.

[60] M. Uschold and M. Gruninger, "Ontologies: Principles, methods and applications," Knowl. Eng. Rev., vol. 11, no. 2, pp. 93-136, 1996.

[61] D. D. Suthers, "Towards a Systematic Study of Representational Guidance for Collaborative Learing Discourse," J. Univers. Comput. Sci., vol. 7, no. 3, pp. 254277, 2001.

[62] A. Osterwalder, "The Business Model Ontology-a proposition in a design science approach," 2004.

[63] Osterwalder A., Pigneur, Y. (2002) An eBusiness Model Ontology for Modeling eBusiness. In Bled 2002

Proceedings, AIS Electronic Library, 75-91.

[64]M. Uschold and M. King, Towards a methodology for building ontologies. Citeseer, 1995.

[65] R. A. Burkhard, "Strategy visualization: A new research focus in knowledge visualization and a case study," presented at the Proceedings of I-KNOW, 2005, vol. 5.

[66] K. Platts and K. Hua Tan, "Strategy visualisation: knowing, understanding, and formulating," Manag. Decis., vol. 42, no. 5, pp. 667-676, 2004.

[67] K. A. Piirainen, G. L. Kolfschoten, and S. Lukosch, "The joint struggle of complex engineering: A study of the challenges of collaborative design," Int. J. Inf. Technol. Decis. Mak., vol. 11, no. 6, pp. 1087-1125, 2012.

[68] A. Osterwalder and Y. Pigneur, "Designing business models and similar strategic objects: the contribution of IS," Journal of AIS., vol. 14, no. 5, p. 237, 2013.

[69] F. Détienne, "Collaborative design: Managing task interdependencies and multiple perspectives," Interact. Comput., vol. 18, no. 1, pp. 1-20, 2006.

[70] M. S. Kleinsmann, "Understanding collaborative design," 2006.

[71] M. J. Eppler, "What makes an Effective Knowledge Visualization? A Review of Seminal Concepts," 2011.

[72] A. Comi and S. Bresciani, "Design Thinking and Techniques in Management Teams: Understanding the Role of Visual Facilitation," 2017.

[73] A. Gómez-Pérez, "Evaluation of ontologies," Int. J. Intell. Syst., vol. 16, no. 3, pp. 391-409, 2001.

[74] R. J. Sternberg, "Implicit theories of intelligence, creativity, and wisdom.," J. Pers. Soc. Psychol., vol. 49, no. 3, p. $607,1985$. 